\title{
Articles
}

\section{Searching for home: Explorations in new media and the Burmese diaspora in New Zealand}

\section{ABSIRACI}

This study examines the place of new media in the maintance of Burmese diasporic identities. Political oppression in Burma, the experience of exile and the importance of opposition movements in the borderlands make the Burmese diaspora a unique and complex group. This study uses tapoetetha$k o t$, an indigenous Karen research methodology, to explore aspects of new media use and identity among a group of Burmese refugees in Auckland, New Zealand. Common among all participants was a twin desire to share stories of suffering and to have that pain recognised. Participants in this project try to maintain their language and cultural practices, with the intent of returning to a democratic Burma in the future. New media supports this, by providing participants with access to opposition news reports of human rights abuses and suffering; through making cultural and linguistic artifacts accessible, and through providing an easy means of communication with friends and family in Burma and the borderlands.

Keywords: Burma, Karen, refugee, diaspora, indigenous, political activism, new media, tapotaethakot

\section{VIOLET CHO}

Asian Journalism Fellow 2009, Pacific Media Centre

7 HIS ARTICLE is about the use of new media in making and maintaining Burmese ${ }^{1}$ cultural, social, political, national and ethnic iden-

1 tities in Auckland, New Zealand. The use of new media among the Burmese diaspora is a means of sustaining bonds with the home country and 
creating a transnational diasporic community. New media can be defined as online media, including internet forms of traditional print, radio and TV, as well as newer participatory types of media such as social networking, chat, video and audio sharing. Through an exploration of how the internet features in the Burmese refugee community in Auckland, this article will examine ways the internet is used to maintain, reconstruct and change political, ethnic and cultural identities.

While there is a significant amount of literature related to media and diasporic identity, there have thus far been less work that focuses specifically on connections between new media and the multiplicity of social and political identities among displaced, exiled groups. A number of studies have been conducted finding that new media is important in allowing diasporic groups to access home culture artefacts (Hiller \& Franz, 2004; Kang, 2009). According to Kang, 'internet use becomes critical in diasporic everyday lives in that it is an important method of bringing homeland and home culture into migrant's daily lives abroad' (Kang, 2009, p. 328). Kang found that many Chinese migrants maintain their identity as Chinese in diasporic sites by using the internet to obtain information, cultural products and other resources (Kang, 2009, pp. 327-343). New media can also be understood to be a source of empowerment for members of diaspora communities to participate in the public sphere in the host country, their country of origin and across international boundaries. 'Diasporic media can be a powerful agent of the community they represent and they can create powerful images of self-representation for the group.' (Husband, Cottle, King \& Wood, cited in Georgiou, 2006, p. 13). This study aims to expand on this literature through a specific case study of new media and the Burmese diaspora, taking into account the interrelatedness of political, ethnic, religious and youth identities.

As an indigenous Karen ${ }^{2}$ woman doing research into Burmese diasporic identities, I have struggled to find a methodology that is appropriate to my identity and the identity of my community. There are no Karen universities and no current practice for translating our culture into a Western academic form. We have no academic journals in Karen languages. Our languages come from an oral tradition and it has been heavily influenced by British colonisation. As a Burmese, knowledge production inside my country is extremely restricted, universities are under-funded, subject to strict censorship and plagiarism is widespread. Burmese and Karen people in foreign universities, working in a 
system and language other than their own, can easily become alienated, as I felt when I started studying in New Zealand. It is therefore important for Burmese and/or Karen researchers to work with methods of research and knowledge production that are not alienating to themselves and their participants.

To look at other options, I started exploring indigenous research methodologies and Indigenous ways of knowing. According to Kovach, indigenous epistemology involves 'incorporating an indigenous theoretical perspective and using aligned methods (e.g., qualitative interviews, storytelling)' (2005, p. 22). Kovach develops an indigenous methodology, following these key principles: '(a) experience as a legitimate way of knowing; (b) indigenous methods, such as storytelling, as a legitimate way of sharing knowledge; (c) receptivity and relationship between research and participants as a natural part of the research "methodology"; and (d) collectivity as a way of knowing that assumes reciprocity to the community,' (2005, p. 28). All of these ways of knowing, and principles for research, are appropriate for myself as a Karen researcher and the community I am researching.

There is, though, a key contradiction between my Burmese identity and my Karen identity. Burmese has a literary tradition while Karen does not. Therefore the written form could be seen as more central to Burmese culture. According to oral history, Karen people had a written tradition with their own alphabet but this was later lost (Saw Aung Hla, 1999). The current Karen alphabets were invented by missionaries who started converting Karen in the early 19th Century. Karen written tradition today is therefore very new and heavily influenced by colonialism. As I feel that my primary community and culture is Karen, I wanted to use a methodology that might be congruent with Karen identity.

\section{The concept of tapotaethakot}

A foreign language isolates me in fundamental ways. Meyer has pointed out the 'difficulty of using language that is not one's own in constructing knowledge' (cited in Kovach, 2005, p. 26). This is a problem for anyone writing in a language that is not their own. As writing this necessitates thinking in English, it can feel like I am cutting myself off from my Karen-ness. For me, thinking in Karen is natural but it is not something I can do when I have to write an article in English, as a foreign language and foreign system. Absolon and Willet, who are First Nation Canadians, have written that being 
from a non-English background 'has given us unique epistemological lenses. Cultural world views are embedded in language' (2005, p. 114) . They call for a process of renaming, which involves using or reinventing indigenous terms and concepts. They justify it as follows: 'In order to express ourselves, we have no choice but to break these rules to make the words work for us, or to create new words' (Absolon \& Willett, 2005, p. 114).

As I could not find a word in English to express how I think a research methodology for this study could work for myself, and my community, I have decided to use a S'gaw Karen word, tapotaethakot. Using such a word is also important as part of an attempt to use Karen language for knowledge production and to give power to Karen ways of seeing and knowing. Tapotaethakot means informal conversation with people who are close. This closeness is intrinsic to Karen culture, where the social norms are to treat others as relatives. One should treat an older man as an uncle, a younger girl as a little sister. There is no appropriate word for tapotaethakot in English. The closest could be 'chatting' but that does not involve kinship relations.

Applied to research methodology, tapotaethakot can include the following principles, which are culturally appropriate to all people of Burma:

1. respect participants and treat them according to local rules of kinship, as if they are family members.

2. meet informally and have conversations rather than formal interviews, sharing food. This also involves reciprocity so the researcher should disclose personal information about herself and her family, and not just expect to take information. This also means I am part of the research and my own experiences do not need to be hidden in 'objective' language. I will attempt to incorporate some reflexive and auto-biographical elements into the work.

3. be open, direct and upfront about the research and purposes of the project.

4. be a community member, involved in and supporting community initiatives. For example, through this research, I have come to know members of a Karen youth group. I have given assistance to them in planning and translation. I am not using the community for the research but rather I am trying to be a useful part of the community.

5. Tapotaethakot also means recognising and valuing people's experience and experiential knowledge. 
6. Recognise and make use of oral tradition and storytelling as legitimate forms of knowledge and research practice. This research project has therefore also involved the production of five short radio features, as a way of affirming Karen oral tradition.

7. Recruit research participants through personal and family relations, and through community leaders in an informal way. I have come to know all of the participants since I arrived in Auckland. I met two of them in a protest; one at a cultural event and another participant was introduced to me by friends in the diaspora in Thailand. They all are actively involved in the Burmese community here and some have close connections with Burmese opposition groups along the border as well as in Burma.

I have therefore used tapotaethakot as my methodology and under this model, I was granted ethics approval by AUT University. The research project involved 14 participants, of whom eight were Karen, three were Burman, one was Chin, one was Karenni and one was Mon. The heavy Karen representation reflects my own Karen identity and my relationships with the Karen community as a starting point. I have used pseudonyms in this article in order to protect the privacy of participants. I have carried out most of the interviews in participants' homes. I did not conduct interviews until after at least one visit where we would share our experiences and eat a communal meal, which are integral for building trust. I have tried to incorporate my own experience and informal conversations with participants into the findings. This is not a representative sample of Burmese people, which would be impossible because of the complexity of political, ethnic, linguistic, class, subcultural and gender identities. The findings here instead reflect the experiences and viewpoints of some of my new friends in New Zealand.

\section{Imagining home in diasporic (cyber) space}

The internet plays an important role in maintaining continuity between the new lives of Burmese refugees in Auckland and their past lives in Burma or the borderlands. For those in the diaspora, the experience of becoming a refugee, leaving Burma and fleeing to Thailand, India or Malaysia is something participants do not want to forget. The internet is therefore a tool to overcome anxiety over 'forgetting'. The concept of diaspora is therefore useful in this instance-since all research participants left Burma with the dream 
to return. One strategy to keep this dream alive is through the consumption of exile based Burmese news media, which is available in English, Burmese and a number of ethnic minority languages. Participants read news not as a disengaged audience but in a highly personal manner where they connect with home and think about family and friends who may be suffering in the locations written about. In one case, Htoo Say, a Karen man from Auckland's western suburbs, even heard about a personal tragedy through exiled news media. Htoo Say had not had any contact with his immediate family, who remained in Burma. One of his first cousins, who was an insurgent soldier, was shot in a military offensive and Htoo Say only found out about it through exiled media in Thailand when a story was published online. Staying 'up to date' with news in Burma also helps maintains plans and dreams of return.

Participants also talked about a sense of belonging to virtual Burmese communities, in contrast to feelings of alienation in New Zealand. This contrast is particularly strong because the majority of participants came to live in New Zealand less than five years ago and none of them identified as New Zealanders. A contributing factor to this is a lack of English skills, which is an essential requirement to be able to build up meaningful relationships with people outside one's ethnic/national group. Three participants explained how they felt secure living in New Zealand compared to previous times when they had to flee fighting. However, they were still not happy because they did not feel like New Zealand was their home.

Participants whose families had been left behind have a particularly strong connection to Burma and/or the borderlands. All participants said they still have relatives back in Burma, however the closeness of the relatives varied, ranging from parents and siblings to more distant cousins. Participants could feel closer to relatives through knowing news in their locales and more directly, through the use of instant messenger and Voice Over Internet Protocol (VOIP) technology. The internet was the primary instrument for personal communication by the majority of participants. Wah Wah, a Karen woman who has recently arrived in New Zealand explained how she uses the internet to keep in touch with her friends:

I have contact with all of my close friends who I knew before. Some of them are in countries like Australia, USA, Russia and Sweden with their families so we live far away from each other but we have regular contact through internet services like email and chat programmes. 
Among ethnic minority participants, ethnic language community media operating in exile are significant in supporting diaspora members to maintain a sense of ethnic identity by reading in minority languages and keeping up to date with ethno-nationalist politics. All Karen and Chin participants said that a key reason that they regularly use minority-language media was for linguistic reasons. They felt that if they often read news in their minority language, it would keep them in practice with that language, and therefore maintain a sense of culture and identity. Nay Moo, a Karen participant said, 'in a country where everyone speaks English, it is important to read Karen language news. We are worried that our language may be lost so we need to read in it regularly to maintain it.' He went on to explain the importance of accessing Karen language media after experiencing repression in Burma:

I grew up in a refugee camp where everyone spoke Karen. I went to a Karen language school and, in that situation, we didn't need to worry about losing the Karen language, but here when we go to school and talk with friends, it is all in English. The only time we can read Karen language is through reading news and speaking at home with our families. So we are in a position where we could lose our language. It is also important-in Burma we are not allowed to learn Karen in school so the language could be lost one day if we don't maintain it.

For this participant, therefore, simply reading news in Karen is a political act of resistance against threats to the language, both in Burma and in the diaspora. Because of this concern, the Karen, Mon and Chin communities in Auckland are also organising language classes for their children. Because ethnic minority identity is so connected to language in the participants' minds, passing on the language to children is fundamental to maintain ethnic identity among their children.

For most ethnic minority participants, a feeling of persecution is part of their ethnic identity. As a result of decades of civil war, being Karen, for example, now means fighting, fleeing and suffering. Minority ethnicities are connected with the sense of being a victim of the Burmese government and/ or Burman domination. Arguably, the fact that exiled media content largely consists of human rights stories contributes to an identity of victimhood amongst those in the diaspora. ${ }^{3}$ For one participant, 'reading Kwekalu [a Karen language online news service] everyday is important because we get 
to know up to date information about Karen people, for example how they flee fighting, how many get killed and the food problems.' This maintains a sense of persecution and strengthens feelings of solidarity with those back home. Guilt is a key emotion within this process. Some participants expressed feelings of guilt because of their relatively privileged and safe position in New Zealand, compared to those left behind. Mahn Tin Htun, a local Karen community leader, commented:

Here in New Zealand, we don't need to worry about our basic living conditions. We don't need to worry about our survival. If you want to eat something, you can eat it. Our kids can go to school, without worrying about where the school fees will come from. But our people back home are suffering - they don't have enough food to eat. We shouldn't enjoy our life here so I encourage everyone to think about what's going on and do something for people back home.

This feeling of guilt is one factor that pushes people to take part in political activism. One participant explained that he is only in New Zealand because of his family and the fact that his child has a disability. He said he felt 'selfish' leaving his comrades behind to come to a comfortable and safe life in Auckland. 'Because I have been working as an activist in the border, when I arrived here, I felt like I needed to show that I can continue that. My comrades keep working so regardless of place, I need to keep working. I need to work even harder than friends back home and do more because I am in this good place now.'

While loss of language is a key concern for ethnic minority participants, non-minority Buddhists seemed more concerned with loss of religion. As Buddhism is so important in Burma, it is unsurprising that it is also a key force for the diaspora also. Within this study 50 percent of participants are Buddhist, including one monk. In Auckland, there are three Burmese monasteries, of which two are rented suburban houses and one is an official monastery. Two of these monasteries are broadly Burmese and one is Mon, and each monastery has one monk. The funds to maintain the monasteries come from private donations from within the Burmese community. Access to monks is crucial for Buddhist Burmese. Htein Lin commented,

It is very important for us to have a monk in a country where we are in a minority group. At the same time, as Buddhist people we need monks 
to lead ceremonies like birthdays, funerals and Buddhist holidays. We are not Christian, we can't go to churches so we need these monks.

Living as a minority in a secular country, many parents have concerns that they will not be able to bring up their children to be 'good Buddhists.' Htein Lin, who has a six-year-old daughter, explained that because he is Buddhist, he wants his daughter to grow up Buddhist so he makes an effort to bring her to the monastery and to teach her about the religion. For him, new media is a key tool to get Buddhist information and audio in order to pass on the religion to his daughter.

I download songs, prayers from websites that focus on Buddhism and let my daughter listen to them. As she is young, she cannot learn many things, like how to read scriptures, so listening to voices is more effective. It also teaches her to pray before she sleeps every night.

In contrast, parents who either do not have internet access or are computer illiterate struggle to find resources for teaching their kids. Myar, a Karenni woman, explained: 'I can't force my kids. They seem uninterested in my Buddhist/Animist religion. Now they just go to the church with friends rather than the monastery.'

\section{New media and activist identity}

For most research participants, the meaning of political identity, in the context of the Burmese democracy movement, means being associated and allied with one or more of the many organisations that oppose the military regime, as well as identifying with 'the movement' generally. There is a joke among democracy activists in exile, that if you have three Burmese in a room, they will represent four organisations. One of my initial interests before undertaking this study was how people sustain political identities when they are so isolated from the movement for democracy in Burma, and how much truth there is to this joke. In particular, Burmese activists who have been involved with organisations that oppose the dictatorship have strongly emphasised the need to belong to opposition groups after they resettle. I also feel that. The first organisation that I joined when I was 14 years old was the Karen Student Network Group, which is a youth organisation founded by young refugees in Thai border camps to raise awareness about Burma's 
political situation among youth in the camp and to maintain and preserve Karen culture while we are away from our country. I joined this organisation in order to find an answer to the question of why I was a refugee living in a camp. I became aware of the social and political situation in Burma after I joined this organisation and it encouraged me to be active and work for the cause of democracy in Burma. I am always proud to identity with this organisation and this is a story that I also share with my other fellow Burmese who are already involved in this political movement. Telling the story about how we got involved in the political movement is a common topic. This kind of storytelling about our own experiences and history took place when I met many of the research participants. This is an important way of building friendship and trust. There are four participants in my research project who proudly identified themselves as still being members of resistance groups, although they could not maintain direct involvement in the organisations since arriving in New Zealand.

Three participants claimed that communication with their colleagues and friends from both inside and outside Burma, through the internet, encouraged them to be politically motivated. XXX ethnic Burman participant who has friends inside and outside Burma could identify activities that he could do from New Zealand, through discussions with activists in the borderlands on Google Talk: 'I always talk to friends who live on the Burma-India border and by talking to them I get updated news that gives me hope and motivation to keep working for the cause.' I was able to listen to an online conversation between this participant and one of his friends, a senior Burmese politician based in New Delhi. His friend, who regularly travels to Burma secretly, gave an update on the underground movement, encouraging more fundraising to support activist networks inside Burma. Online chatting with friends who have access to high speed interent is a regular phenomenon for many participants. However it is harder to use chat technology with those inside Burma, because of the expense of internet cafes and internet surveillance by the government. This limited some participants from communicating with activist friends in the country.

Spreading news gathered online was one of the most basic forms of activism amongst research participants. Because not all in the Burmese diaspora have access to the internet and read news, those who do often take it as a duty to inform others about what is going on, particularly in relation to 
human rights and political developments. For two participants, summarising daily news that they gathered from the internet to others was an important political action, which they tried to do everyday. One participant said that telling people up-to-date news encourages them to take part in activist events, such as memorial days and protests. The feeling of satisfaction from sharing news and information from websites is also connected to Nichols' concept of epistephilia, which he defines as 'a desire to know' (2001, p. 40). Nichols, writing about documentary film, explained that 'He-Who-Knows (the agent has traditionally been masculine) will share knowledge with those who wish to know. We, too, can occupy the position of The-One-Who-Knows. They speak about them to us and we gain a sense of pleasure, satisfaction, and knowledge as a result' (2001, pp. 40-41). The appeasement of guilt and the feeling of action from 'knowing' and being in a position to spread knowledge is an important motivation behind Burmese activists who make this part of their routine. As Nichols has said, 'power and responsibility reside in knowing' (2001, p. 41). The unequal language and technical skills within the Burmese diaspora create a division then, between those who 'know' and those who wait to be told.

For some participants with greater English language skills, part of activism is spreading online Burmese news to non-Burmese people. When I talk with New Zealanders, they constantly express sympathy because Burmese people are so often portrayed as victims in mainstream media. One participant expressed the importance of telling New Zealanders about human rights abuses in Burma in order to gain their sympathy. Since there are few concrete actions New Zealanders can do, recognition of suffering is like a political act in itself and the desire to garner expressions of sympathy is one part of local diaspora activism. Some participants seem to internalise the human rights news they read in exiled media, which possibly heightens their feeling of victimhood.

Buddhism is also an important identity for political activists in Auckland. Kyaw Ko, a participant who is a political activist, equates being a Buddhist with national identity and thereby saw the loss of Buddhism as the loss of Burmese national identity. Generally, the religion is placed in the highest position in society and the monks are treated as the sons of Buddha. It is common to see monks take part in political events and their appearance in social and political anniversaries and rituals is significant for Burmese inside Burma and in Auckland. Kyaw Ko explained how he worked with one of the refugee monks in Auckland: 
We invite the monk to all of our political anniversaries because he is a spiritual leader and he has the highest position in our community. We do not have a Burmese state minister or state representatives that we can invite to our important political events, so we invite him instead. His appearance in the event is also important because he is an influential figure for Burmese people here and people give respect to him as someone who is even more than a monk. Rather, he is a revolutionary monk.

These political events organised in Auckland with the participation of monks has another agenda. It is clearly organised to set an example for young Burmese who arrived here when they are young or those born in this new country. According to Burmese political activists involved in this study, an important task for those whose Buddhist and political identities are intertwined, is to pass these ways of seeing down to their children, as Htein Lin explained:

It is important for us to organise political events that include monks because we need our young generation to learn these things. It is more crucial for us to do this because we understand that there is a very limited chance for our young people to see this kind of political activity that includes monks, if we do not initiate it.

Only one participant, Sayadaw, is a monk, who also identified as an activist. The internet was a key medium for his activism. Sayadaw was part of the Young Monks' Buddhist Association, and actively supports the monks' movement inside Burma through fundraising and giving advice and encouragement. For him, the internet is the most important tool for his activism. He uses it to keep in touch with his colleagues in Burma and around the world, through email and instant messenger programmes:

I use internet everyday and chat with my colleagues inside Burma and other countries and find out the latest information. Buddhism is linked with ideas of peace and justice so when the country is in trouble, it is considered to be part of the responsibility of monks to address these problems. This is the reason monks took to the streets in 2009.

Buddhism is important for political legitimacy in Burma (Steinberg, 2006). This is also true in Auckland, where one refugee monk attends and blesses key political events, such as protests, Aung San Suu Kyi's birthday 
and the anniversary of the 1988 uprising. Sayadaw's presence at such events indicates connections between Buddhism and Burmese identity and the importance of religious blessing at protests for this diasporic group.

In this study, an explicitly political identity was only important for Burmese adults in their thirties and forties. Identifying oneself with political organisations, even that of one's parents, appeared to be outside of the concerns of young Burmese in their teens and twenties, especially young people who were born in New Zealand or those who arrived here at a very young age. Refugee youth are involved in activism but it seems to have a more cultural focus. The internet has, for example helped Karen youth establish a group which, at the time of writing, comprises about 30 young people in Auckland who organise themselves with the objective of preserving Karen culture and traditions. This group was successfully set up after one young leader and his colleagues in Auckland had seen and learnt cultural-based activities online, which were carried out by Karen communities overseas. The youth group was established in response to the perceived inaction of senior New Zealand-based Karen organisations. Nay Moo, the group leader explained the motivation behind the new group:

Through the internet, I have read news and seen pictures of Karen rituals such as the wrist tying ceremony and Karen New Year that were organized by communities in Australia, the USA and the UK. We could not do things like that in New Zealand before so this encouraged me to set up a youth group to organise these necessary cultural activities.

At the time of writing, they were preparing for a Karen New Year event. This has involved weekly practice for the dohn dance, an important Karen performance involving music, singing and dancing with a large group of people. To coordinate the dance takes a lot of practice and cooperation. The internet was a key tool for organising this locally, as clips of dohn dances on YouTube were the main reference for the choreography. Within the youth group, members communicate through web-based technologies such as email, internet to mobile phone texting and instant messenger programs, which are free, allowing them to cut operational costs associated with phone calls and mobile phone text messages. 


\section{Conclusion}

New media has fundamentally influenced the everyday living spaces of the Burmese diaspora community in Auckland. According to this study, internet use is widely available among the diaspora, and it is used in different ways, depending on how people view themselves and what is important to their identity. For participants from ethnic minority backgrounds, maintaining language and culture was of key importance. Those participants tended to use the internet to read and listen to music in their own language, which was often articulated as a type of resistance to the perceived threat to their languages from the Burmese government. For Burman participants, maintaining Buddhism and passing it down to their children was also significant, however the perceived threat for them came the possibility of losing their Burmese identities in New Zealand, rather than internal politics in Burma. It appears that online media, which has a heavy emphasis on human rights stories, also leads to a feeling of victimhood among participants, even if they have not directly experienced persecution. However further studies should be done to examine this.

For participants with connections to political groups in Burma or the borderlands, the internet was important in maintaining their ties and keeping them up-to-date, which sustain their identity and actions as activists. For all participants, the internet was useful for keeping in touch with friends and relatives, thereby maintaining their links to their homeland and thus their sense of belonging to Burma. Most of my participants identified as oppressed. The sense that wrongs had been done to them by the Burmese military government was important. Having faced this oppression and then fleeing as refugees was a fundamental part of the identities of virtually all of my respondents. Common among all participants was a wish to keep their Burmese identities, which included a sense of being victimised. As such, the desire of those I interviewed to identify as Burmans, Karen, Karenni or Mon was as much concerned with the political struggles they had left behind as an attempt to resist assimilation in to New Zealand.

As I am also a Karen/Burmese refugee who speaks their language and has suffered like them, I can communicate with them in a deep way. When I meet participants, we tell each other stories about exile, which is a way of recognising each other's suffering and thereby keeping each other's identity as Burmese refugees who have resisted an oppressive regime. In my research, 
it was very important that I was able to speak with participants in their own language. If I was not able to do so then I probably could not have entered their private sphere in the same way. My own identity as a Karen refugee in the interviews and the use of tapotaethakot as a methodology led to the development of relationships that involved recognition of our shared mutual experience.

\section{Notes}

1. In this research, the term 'Burma' and 'Burmese' is being used to refer to the country and nationality. In 1997, the Burmese military government changed the name of the country to Myanmar. The word Myanmar and Burma derive from the same root, however 'Burma' has been linked to British colonial rule. Because the country name was changed in an undemocratic way by military authorities, the Burmese opposition has rejected it, and continue to use the term 'Burma', as is done in this dissertation. The term 'Burman' is used to refer to the dominant ethnic group in the country, while 'Burmese' refers to the nationality, regardless of ethnicity.

2. Karen is a complex term with no fixed meaning. I am using it to refer to a diverse range of linguistic, religious and political groups. The two main Karen languages are S'gaw and Pwo, both of which the author speaks.

3. Examples of human rights-focussed exiled media can be found at www.bnionline. net.

\section{References}

Absolon, K., \& Willett, C. (2005). Putting ourselves forward: location in aboriginal research In L. Brown \& S. Strega (Eds.), Research as resistance: critical, indigenous, \& anti-oppressive approaches (pp. 97-126). Toronto, Ontario Canadian Scholars' Press/Women's Press.

Georgiou, M. (2006). Diaspora, identity and the media : diasporic transnationalism and mediated spacialities. Cresskill, N.J.: Hampton Press.

Hiller, H. H., \& Franz, T. M. (2004). New ties, old ties and lost ties: the use of the internet in diaspora. New Media \& Society, 6(6), 731.

Kang, T. (2009). Homeland Re-Territorialised. Information, Communication \& Society, 12(3), 326-343.

Kovach, M. (2005). Emerging from the margins: indigenous methodologies. In L. Brown \& S. Strega (Eds.), Research as resistance: critical, indigenous, \& antioppressive approaches. Toronto, Ontario: Canadian Scholars' Press/Women's Press.

Nichols, B. (2001). Introduction to documentary. Bloomington, Ind.: Indiana University Press.

Saw Aung Hla. (1999). K'nyaw Ali Ta Sisoh Tehsoh. Chiang Mai, Thailand: Images Asia.

Steinberg, D. I. (2006). Turmoil in Burma: contested legitimacies in Myanmar. Norwalk, Conn.: EastBridge. 
Violet Cho is an ethnic Karen refugee who writes for Irawaddy magazine in Thailand. She was the first Asian journalist to come to New Zealand under the AUT Pacific Media Centre's inaugural Asian Journalism Fellowship funded by the Asia New Zealand Foundation in 2009. Cho, who fled Burma with her family to begin life in a Thai refugee camp in 1991, was a resource journalist with the PMC for staff and students during her time in New Zealand. She also completed a BCS (Hons) dissertation on the Burmese diaspora at AUT.

\section{//Annual \\ conference}

1 \& 2 December 2011

City Campus, Wintec, Hamilton, Waikato

Convenor: Charles Riddle

Ph: +64 78348800

Email: Charles.riddle@wintec.ac.nz
Abstracts: Jim Tully

Ph: +64 33642881

Email: jim.tully@canterbury.ac.nz
Registration: Jeremy Smith

Ph: +64 78348800

Email: Jeremy.smith@wintec.ac.nz 